\title{
Trabecular Meshwork at the Left Ventricular Apex
}

\author{
Shuhei Misumi ${ }^{1}$, Ikuo Misumi ${ }^{1}$, Seigo Sugiyama ${ }^{2}$ and Hisao Ogawa ${ }^{2}$
}

Key words: three-dimensional echocardiography, left ventricular noncompaction

(Intern Med 50: 2685-2686, 2011)

(DOI: 10.2169/internalmedicine.50.6373)

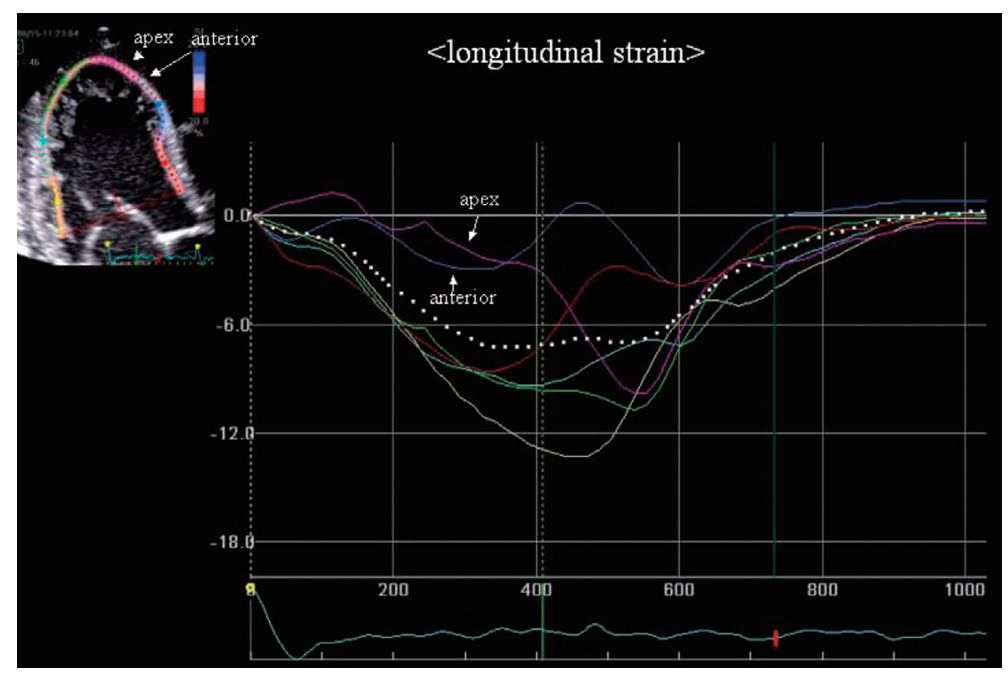

Picture 1.

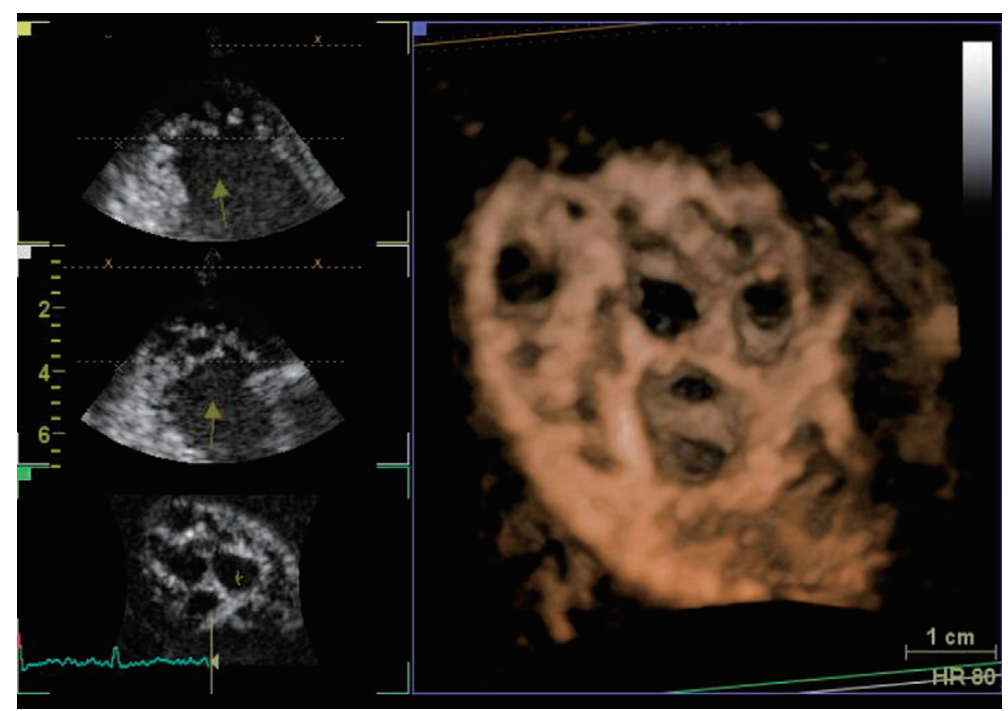

Picture 2.

${ }^{1}$ Department of Cardiology, Kumamoto Saisyunsou Hospital, Japan and ${ }^{2}$ Department of Cardiovascular Medicine, Graduate School of Medical Sciences, Kumamoto University, Japan

Received for publication August 12, 2011; Accepted for publication August 15, 2011

Correspondence to Dr. Ikuo Misumi, misumi@ saisyunsou1.hosp.go.jp 
A 73-year-old man with recurrent cerebral infarction was referred to our department for the treatment of heart failure. Electrocardiography (ECG) showed atrial fibrillation, low voltage in the limb leads, and a QS wave in the precordial leads. Two-dimensional echocardiography showed that the left ventricle was enlarged and diffusely hypokinetic. Because echocardiography showed marked thickening and severe trabeculation of the left ventricular apex, the patient was diagnosed with noncompaction of the left ventricle.
Longitudinal strain assessment showed distinct systolic dysfunction of the noncompacted apical segment (Picture 1). Three-dimensional echocardiography of the apex showed that the large trabeculae were not isolated but rather were connected to each other by a meshwork structure (Picture 2). Three-dimensional echocardiography was useful to reveal the structure of the left ventricular noncompaction.

The authors state that they have no Conflict of Interest (COI).

(C) 2011 The Japanese Society of Internal Medicine http://www.naika.or.jp/imindex.html 